\title{
Source Document
}

National Cancer Institute

\section{Source}

National Cancer Institute. Source Document. NCI Thesaurus. Code C142692.

The original information in a variety of media, which may substantiate information contained in an electronic record of the study. 